\section{$\underset{\substack{\text { hommes } \\ \text { \& migrations }}}{ }$}

\section{Hommes \& migrations}

Revue française de référence sur les dynamiques

migratoires

$1334 \mid 2021$

Exposer le racisme et l'antisémitisme

\title{
Faïza Guène, La Discrétion
}

Paris, Plon 2020, 256 p., $19 €$.

\section{Mustapha Harzoune}

\section{(2) OpenEdition}

1 Journals

\section{Édition électronique}

URL : https://journals.openedition.org/hommesmigrations/13141

DOI : 10.4000/hommesmigrations. 13141

ISSN : 2262-3353

\section{Éditeur}

Musée national de l'histoire de l'immigration

\section{Édition imprimée}

Date de publication : 1 juillet 2021

Pagination : 231-232

ISBN : 978-2-919040-58-2

ISSN : $1142-852 X$

Référence électronique

Mustapha Harzoune, «Faïza Guène, La Discrétion », Hommes \& migrations [En ligne], 1334 | 2021, mis en ligne le 01 juillet 2021, consulté le 04 février 2022. URL : http://journals.openedition.org/

hommesmigrations/13141; DOI : https://doi.org/10.4000/hommesmigrations.13141 


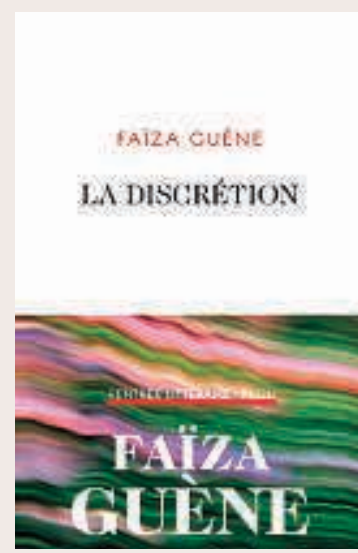

(jamais univoque). Les Taleb forment une famille française pure sucre, comme dans les romans de Sabri Louatah par exemple. Enfin presque, car il y a du chemin pour faire entrer cette vérité dans les têtes, pour que «les choses soient plus simples» et que cela soit «plus clair pour tout le monde».

Au centre, il y a la mère. La discrète, l'humble, la généreuse Yamina. Humaine pour dix! Yamina, la douce musulmane qui ne fait pas de son voile une barrière, qui offre couscous et pâtisseries à son voisinage lequel lui retourne des assiettes... vides. Écarts culturels!

Que sait-on d'ailleurs de ces hommes et de ces femmes qui se sont installés - souvent contraints en France, y ont abandonné leurs rêves, épuisé leur énergie, et fait des enfants qui les ont enracinés plus sûrement qu'une énième loi sur l'intégration? Pas grand-chose. Alors Faïza Guène ne se contente pas d'exposer le quotidien de cette femme en banlieue parisienne. Elle livre un peu de sa vie, retrouve le chemin de l'intime, en restitue sa part d'humanité. Naissance dans une Algérie française qui ne partageait de la civilisation que la misère et la relégation; enfance en guerre marquée par l'absence

\section{La Discrétion}

Faïza Guène, Paris, Plon 2020, 256 p., $19 €$

Chez Faïza Guène, la famille est une porte d'entrée. Elle dévoile les interactions entre le particulier (toujours divers) et le collectif du père et l'exil au Maroc; jeunesse dans un pays indépendant mais dur pour les siens passés des colons aux colonels. Pourtant, pour Yamina, la vie pouvait être douce auprès des siens, de son père, du vieux et lointain figuier, aujourd'hui 
ressuscité dans un jardin ouvrier d'Aubervilliers où elle fait pousser non pas des piments mais... des œillets d'Inde.

Faïza Guène déjoue les codes et les stéréotypes. Elle ne sert pas de la victimisation et du machisme, de la violence patriarcale, de l'islam sectaire et gris (malgré un burkini incongru). Brahim aime sa femme et ses enfants. Omar, le fiston - et le chouchou! - chauffeur Uber, est un tendre, intranquille socialement et gauche avec les filles. Les trois frangines, dans la tradition de ce pays, offrent une palette élargie de Françaises aux origines mêlées. Malika, l'aînée, est agent d'état civil à la mairie de Bobigny. Hannah est éducatrice spécialisée. Imane a quitté le domicile familial, vendeuse à Maxi Toys, elle a mal au dos à 31 ans. Aucune n'est mariée. Pas trouvé d'homme à la hauteur... «du daron»! Imane n'imagine pas un Oliver Barrett dans le salon familial. Hannah, qui ne dédaigne pas un peu de virilité, endure des amants pleurnichards, mais ne supporte pas ces "garçons arabes», "morceaux de sucre dans un café chaud» qui préfèrent une «femme blanche aux cheveux raides». Malika est divorcée. Une honte et, surtout, une mort pour les femmes. "Pour les femmes seulement». Un mot et tout est dit.

Ces quatre-là se coltinent colère, sentiment d'illégitimité, culpabilité, emberlificotés qu'ils sont dans les trous de la transmission, le désintérêt, voire le mépris, de la société pour leurs parents, les legs de la colonisation et ses resucées, les bavures et les contrôles au faciès, les menaces de déchéance de la nationalité, les injonctions à «se désolidariser» après un attentat - «Un peuple uni ne se divise pas pour pleurer ses morts. » Alors Hannah consulte un psy, pour régler cette «question de la LÉGITIMITÉ », réparer «les impacts» des injustices subies par ses parents qui lui «dévorent les tripes», pour épargner ses (futurs) enfants et briser les chaînes de la culpabilité et de la colère. Il faudrait «réparer l'offense» et que ce monde s'ouvre enfin à «sa complexité». Comme en contrepoint, Nadia, qui «donne le vertige à Omar», à l'aise, «débarrassée de tout complexe, n'a pas envie qu'on discute sa place dans le monde».

Et Yamina! Sa "discrétion» serait-elle de la soumission? Longtemps, la génération des enfants tançait la «faiblesse» des aînés. La mode semble passée. Mais Hannah presse sa mère de protester contre son médecin, contre le chien de la voisine, la fonctionnaire de la préfecture, ou cette sale ambiance qui fait que «qui on est est devenu trop risqué». À moins que Yamina montre plus de force pour aimer qu'à céder aux démons de la haine. Il se peut que son innocence la protège et qu'elle ait «choisi de ne pas se laisser abîmer par le mépris».

Faïza Guène écrit à l'économie et à l'efficacité: un mot suffit à traduire une émotion, une situation, une pensée, l'intime comme le collectif. Elle croque son monde qu'elle connaît bien par ses codes et par son phrasé. C'est souvent drôle, vif, impitoyable.

M. H. 